\title{
Tension-free vaginal tape-Abbrevo procedure for female stress urinary incontinence: a prospective analysis over 22 months
}

Alice $\underline{K u r i e n}^{1}$, mrcog, MD, Sarita Narang${ }^{2}$, Mrcog, MD, How Chuan $\underline{\operatorname{Han}}^{2}$, MRAcog, FRcog

INTRODUCTION We aimed to study the efficacy and safety of the tension-free vaginal tape (TVT)-Abbrevo procedure for female stress urinary incontinence (SUI).

METHODS This was a prospective cohort study that aimed to determine the subjective and objective cure, improvement of SUI and incidence of complications among women who underwent TVT-Abbrevo for SUI during a period of 22 months from September 2011 to June 2013.

RESULTS A total of 76 patients, with a mean age of $48.2 \pm 8.1$ years, underwent TVT-Abbrevo during the study period. Among them, $86.8 \%$ had vaginal delivery and $5.3 \%$ had instrumental delivery. Mean parity was $2.3 \pm 0.8$ and mean body mass index was $27.0 \pm 5.0 \mathrm{~kg} / \mathrm{m}^{2} .11(14.5 \%)$ patients had previously tried physiotherapy. Mean follow-up duration was $12.3 \pm 5.6$ months. The subjective cure rate for SUI at one-month, six-month and one-year follow-up was $95.7 \%, 90.8 \%$, and $90.6 \%$, respectively. Among the nine patients who completed the two-year follow-up, $88.9 \%$ reported either cure or improvement of SUI. At six months, the proportion of patients with objective cure was $86.8 \%$, and the rates of postoperative groin pain and complications were low. In addition, overactive bladder symptoms disappeared in $76.3 \%$ of patients. CONCLUSION Our results are comparable with those of other studies, although long-term results remain to be seen.

Keywords: complications, groin pain, stress urinary incontinence, subjective and objective cure, TVT-Abbrevo

\section{INTRODUCTION}

Stress urinary incontinence (SUI) is characterised by involuntary leakage of urine during rise in intra-abdominal pressure on coughing, sneezing, laughing, lifting or even changing position. It affects about $13 \%-15 \%$ of women, and is more common among Caucasians and Hispanics. The exact pathophysiology of SUI is uncertain, but several hypotheses have been put forward. Pregnancy, childbirth, hormonal changes, ageing, smoking, chronic cough and pelvic surgery increase the incidence of SUI in women. SUI can have a significant detrimental impact on various aspects of quality of life for affected women, such as physical (work, sports, hobbies, travel), psychosocial, sleep, sexual relationships and hygiene. ${ }^{(1,2)}$ Such consequences are the main driving force that prompt affected women to seek treatment to improve the condition.

A urodynamic assessment is recommended if there are associated symptoms suggestive of overactive bladder, voiding dysfunction, anterior vaginal wall prolapse or if the patient had previously undergone surgery for SUI. ${ }^{(3)}$ Lifestyle interventions and medical therapy should be offered prior to surgery in patients with mixed incontinence. Pelvic floor exercise is the first-line treatment for SUI. If conservative measures fail, midurethral tape is the most commonly used surgical procedure. During the last 15 years, various procedures, such as transobturator tape and tension-free vaginal tape-obturator (TVT-O), have been developed to reduce the risks of the original transvaginal tape by Ulmsten et al. ${ }^{(4)}$

TVT-Abbrevo is a modified form of the TVT-O procedure in which a shorter tape $(12 \mathrm{~cm}$ in length) is used with minimal dissection. There is a $32 \%$ reduction in mesh in this modified sling. It is an inside-out procedure similar to TVT-O, but there is no dissection of the obturator membrane with the guide or scissors. The tape forms a hammock under the midurethra and prevents SUI. The shorter mesh length and less dissection in TVT-Abbrevo reduces complications and pain. This enables faster recovery while giving the same tension-free support to the midurethra. The safety and efficiency of TVT-Abbrevo, as well as a reduction in associated groin pain, have been reported by several studies. ${ }^{(5-7)}$ As the procedure is less invasive than TVT-O and technically easier to perform, it provides an obvious advantage for both the patient and the surgeon. Our study aimed to determine the outcome of the TVT-Abbrevo procedure during the study period of 22 months.

\section{METHODS}

All patients with SUI who had undergone TVT-Abbrevo at KK Women's and Children's Hospital, Singapore, during a period of 22 months from September 2011 to June 2013 were included in the study. Patients who had undergone concurrent prolapse repair, vaginal hysterectomy or previous failed incontinence surgery, or had maximum urethral closure pressure (MUCP) $<42 \mathrm{~cm}$ water $\left(\mathrm{H}_{2} \mathrm{O}\right)$ were excluded. Preoperative assessment included focused history-taking, clinical examination, erect stress test, multichannel filling and voiding cystometry, and urethral pressure profile (UPP). Patients were investigated for urinary tract infection (UTI) prior to cystometry and surgery. All patients had a follow-up plan of up to five years in terms of efficacy and complications. Symptoms were assessed and at the six-month

${ }^{1}$ Department of Obstetrics and Gynaecology, 2Department of Urogynaecology, KK Women's and Children's Hospital, Singapore

Correspondence: Dr Alice Kurien, Staff Registrar, Department of Obstetrics and Gynaecology, KK Women's and Children's Hospital, Level 6, Women's Tower, 100 Bukit Timah Road, Singapore 229899. riversideruby@gmail.com 
follow-up, a postsurgery urodynamic study (UDS), including UPP, was done and the results were compared with the preoperative assessment. All patients were followed up for outcome in terms of efficacy and complications. Groin pain was evaluated using a visual analogue scale (VAS; score range 1-10) during the immediate postoperative period, Postoperative Day 1 , the first postoperative visit (Days 3-10), and the one-month, six-month and one-year follow-up visits.

\section{RESULTS}

During the study period, 76 patients underwent TVT-Abbrevo and qualified for inclusion. Among them, 70 (92.1\%) patients had completed one month of follow-up. A total of 66 (86.8\%, $\mathrm{n}=76), 53(96.4 \%, \mathrm{n}=55)$ and all $9(100 \%)$ patients were available for follow-up at six months, one year and two years, respectively. Mean duration of follow-up was $12.3 \pm 5.6$ (range 0.03-26.80) months (data not presented). Defaulters were recalled. The demographic profile of the patients is shown in Table I.

Demonstrable SUI on erect or supine stress test was present in $51(67.1 \%)$ patients (data not presented). Concomitant urgency and urge incontinence (U/UI) was reported in 42 (55.3\%) patients (data not presented). On preoperative UDS, 49 (64.5\%) patients had leakage and 26 (34.2\%) patients had concomitant detrusor overactivity (DO).

Mean duration of surgery was $14.3 \pm 5.7$ (range 6-40) minutes (data not presented). Mean blood loss was $12.4 \pm 10.8$ (range $1-50) \mathrm{mL}$. Out of the 76 patients, $2(2.6 \%)$ had vaginal perforation. There were no bladder perforations. 22 (28.9\%) patients did not require an indwelling catheter (data not presented). Mean duration of continuous urinary drainage with an indwelling catheter was $0.8 \pm 1.0$ (range 0-8) days. Mean hospital stay was $1.2 \pm 0.6$ (range 0.5-4.0) days. Table II shows the operative details, and intraoperative and immediate postoperative complications seen among our patients.

Groin or thigh pain was evaluated in the postoperative period and during the follow-up visits. In the immediate postoperative period (within the first six hours), $43(56.6 \%)$ patients experienced pain. The mean pain score was $1.2 \pm 1.6$ (range $0-7$ ). Only five patients $(6.6 \%)$ had VAS scores $\geq 5$. During the first postoperative review on Days $3-10$, only $7(10.4 \%, \mathrm{n}=67)$ patients had any pain and their mean pain score was $0.2 \pm 0.7$ (range $0-4$ ). At the one-month review, only $3(4.3 \%, \mathrm{n}=70)$ patients had pain and their mean pain score was $0.1 \pm 0.3$ (range $0-2$ ). None of the patients had pain during the six-month and two-year follow-up visits. At the one-year review, $1(1.9 \%, \mathrm{n}=53)$ patient had minimal pain (Table III). Small asymptomatic tape erosion was noted postoperatively in $3(4.5 \%, \mathrm{n}=66)$ patients at six months. There were no wound infections. 1 (1.5\%) patient developed recurrent UTIs in the first six months. None of our patients had persistence of UTI beyond six months (Table IV).

Subjective cure of SUI was seen postoperatively for $67(95.7 \%, \mathrm{n}=70)$ patients at one month, $59(90.8 \%, \mathrm{n}=65)$ patients at six months and $48(90.6 \%, \mathrm{n}=53)$ patients at one year. Among the nine patients who completed the two-year follow-up, $88.9 \%$ reported achieving cure or improvement. The objective cure rate of SUI at six months was $86.8 \%(n=53)$ (data not presented). 23 patients declined postoperative UDS. U/UI disappeared subjectively in $76.3 \%$ and $78.8 \%$ of patients at six months and one year, respectively (Table V).

Preoperative maximum flow rate (Qmax) of $21.6 \pm 13.9 \mathrm{~mL} / \mathrm{s}$ decreased to $17.7 \pm 11.6 \mathrm{~mL} / \mathrm{s}$ postoperatively and postvoid residual (PVR) volume increased from a mean of $11.2 \pm 12.3 \mathrm{~mL}$ preoperatively to $13.9 \pm 11.3 \mathrm{~mL}$ at the six-month postoperative evaluation. There was significant reduction of mean leak amount

Table I. Demographic profile of the patients $(n=76)$.

\begin{tabular}{lc}
\hline Variable & No. (\%) \\
\hline Age $(\mathbf{y r})^{*}$ & $48.2 \pm 8.1(32-70)$ \\
Parity* & $2.3 \pm 0.8(0-5)$ \\
Mode of delivery & \\
$\quad$ Vaginal & $66(86.8)$ \\
Instrumental & $4(5.3)$ \\
Body mass index $\left(\mathbf{k g} / \mathrm{m}^{2}\right)^{*}$ & $27.0 \pm 5.0(16.9-44.9)$ \\
Postmenopausal & $20(26.3)$ \\
Tried physiotherapy & $11(14.5)$ \\
\hline
\end{tabular}

*Data presented as mean \pm standard deviation (range).

Table II. Operative details and early (intraoperative and immediately postoperative) complications among the patients $(n=76)$.

\begin{tabular}{lc}
\hline Variable & No. (\%) \\
\hline Bladder perforation & $0(0)$ \\
Vaginal perforation & $2(2.6)$ \\
Estimated blood loss $(\mathrm{mL})^{*,+}$ & $12.4 \pm 10.8(1-50)$ \\
Hospital stay (day)* & $1.2 \pm 0.6(0.5-4.0)$ \\
Duration of catheterisation (day)* & $0.8 \pm 1.0(0-8)$ \\
Prolonged catheter $\geq 7$ days & $1(1.3)$ \\
Fever & $3(3.9)$ \\
Urinary tract infection within $1 \mathrm{mth}^{*}$ & $4(5.7)$ \\
\hline
\end{tabular}

*Data presented as mean \pm standard deviation (range). +Data was missing for 9 patients (not documented at time of surgery). $¥ 6$ patients did not report for 1-month follow-up.

Table III. Postoperative evaluation of groin or thigh pain using VAS scores.

\begin{tabular}{|c|c|c|c|c|c|c|c|}
\hline \multirow[t]{2}{*}{ Variable } & \multicolumn{7}{|c|}{ No. $(\%) /$ mean \pm standard deviation (range) } \\
\hline & $\begin{array}{c}\text { Day } 0 \\
(n=76)\end{array}$ & $\begin{array}{l}\text { Day 1-2 } \\
(n=71)\end{array}$ & $\begin{array}{c}\text { Day 3-10 } \\
(n=67)\end{array}$ & $\begin{array}{c}1 \text { mth } \\
(n=70)\end{array}$ & $\begin{array}{c}6 \text { mth } \\
(n=66)\end{array}$ & $\begin{array}{c}1 \mathrm{yr} \\
(n=53)\end{array}$ & $\begin{array}{c}2 y r \\
(n=9)\end{array}$ \\
\hline Patients with pain & $43(56.6)$ & $28(39.4)$ & $7(10.4)$ & $3(4.3)$ & $0(0)$ & $1(1.9)$ & $0(0)$ \\
\hline VAS score $\geq 5$ & $5(6.6)$ & $4(5.6)$ & $0(0)$ & $0(0)$ & $0(0)$ & $0(0)$ & $0(0)$ \\
\hline Pain score & $1.2 \pm 1.6(0-7)$ & $1.1 \pm 1.7(0-7)$ & $0.2 \pm 0.7(0-4)$ & $0.1 \pm 0.3(0-2)$ & $0(0)$ & $0.02 \pm 0.1(0-1)$ & $0(0)$ \\
\hline
\end{tabular}

VAS: visual analogue scale 
from $44.7 \pm 94.6$ g preoperatively to $2.5 \pm 11.6$ g postoperatively. The mean postoperative maximum cystometric capacity was $346.2 \pm 126.9 \mathrm{~mL}$ compared to $316.1 \pm 106.9 \mathrm{~mL}$ during the preoperative evaluation. MUCP was $\geq 42 \mathrm{~cm} \mathrm{H}_{2} \mathrm{O}$ in $90.4 \%$ of patients during the postoperative evaluation. DO decreased to $22.7 \%$ postoperatively compared to $34.2 \%$ preoperatively. The

Table IV. Long-term complications seen among patients.

\begin{tabular}{lc}
\hline Variable & No. (\%) \\
\hline Tape erosion & $3(4.5)$ \\
At 6 mth $(n=66)$ & $0(0)$ \\
At 1 yr $(n=53)$ & \\
Recurrent urinary tract infection & $1(1.5)$ \\
At 6 mth $(n=66)$ & $0(0)$ \\
At 1 yr $(n=53)$ & $0(0)$ \\
Tape cutting/loosening/reoperation & $0(0)$ \\
Voiding dysfunction
\end{tabular}

mean urethral functional length increased from $23.9 \pm 10.8 \mathrm{~mm}$ preoperatively to $30.5 \pm 16.3 \mathrm{~mm}$ postoperatively (Table VI).

\section{DISCUSSION}

SUI is the most common type of urinary incontinence in women. About $13 \%-15 \%$ of women experience SUI, although many do not seek medical aid. Epidemiological studies have shown that the peak age for SUI is $45-49$ years. ${ }^{(8)}$ The mean age of patients with SUI in our study was $48.2 \pm 8.1$ years.

Routine preoperative UDS is not a mandatory investigation if genuine SUI is diagnosed clinically in patients. ${ }^{(9)}$ At our centre, voiding cystometry and UPP are done routinely prior to surgery and at the six-month follow-up. Preoperative evaluation with UDS helps to identify patients with intrinsic sphincter deficiency and to select appropriate treatment procedures. A retropubic procedure has been found to be more effective in such patients. ${ }^{(10)}$ Preoperative selection of the patient and appropriate surgical procedure are important for achieving the best cure

Table V. Outcome of surgery.

\begin{tabular}{|c|c|c|c|c|}
\hline \multirow[t]{2}{*}{ Variable } & \multicolumn{4}{|c|}{ No. (\%) } \\
\hline & $\begin{array}{c}1 \text { mth } \\
(n=76)\end{array}$ & $\begin{array}{c}6 \text { mth } \\
(n=76)\end{array}$ & $\begin{array}{c}1 \mathrm{yr} \\
(n=55)\end{array}$ & $\begin{array}{c}2 y r \\
(n=9)\end{array}$ \\
\hline Follow-up & $70(92.1)$ & $66(86.8)$ & $53(96.4)$ & $9(100.0)$ \\
\hline \multicolumn{5}{|l|}{ SUI* } \\
\hline Disappeared & $67(95.7)$ & $59(90.8)$ & $48(90.6)$ & $7(77.8)$ \\
\hline No change & $1(1.4)$ & $1(1.5)$ & $1(1.9)$ & $1(11.1)$ \\
\hline Recurrence & $0(0)$ & $0(0)$ & $1(1.9)$ & $0(0)$ \\
\hline \multicolumn{5}{|l|}{ U/UI+ } \\
\hline Disappeared & $26(65.0)$ & $29(76.3)$ & $26(78.8)$ & $5(71.4)$ \\
\hline Improved & $2(5.0)$ & $7(18.4)$ & $4(12.1)$ & $1(14.3)$ \\
\hline No change & $12(30.0)$ & $2(5.3)$ & $2(6.1)$ & $1(14.3)$ \\
\hline Erect/supine cough stress test (demonstrable)* & $0(0)$ & $2(3.1)$ & $2(4.5)$ & $0(0)$ \\
\hline
\end{tabular}

*One patient left without consultation after urodynamic study at 6-month follow-up. ${ }^{+}$No. of patients in U/UI at 1 month, 6 months, 1 year and 2 years was $40,38,33$ and 7, respectively. ${ }^{*}$ No. of patients in erect/supine cough stress test at 6 months, 1 year and 2 years was 64,44 and 6 , respectively. SUI: stress urinary incontinence; $\mathrm{U} / \mathrm{UI}$ : concomitant urgency and urge incontinence

Table VI. Preoperative and six-month postoperative urodynamic study (UDS).

\begin{tabular}{|c|c|c|}
\hline \multirow[t]{2}{*}{ Variable } & \multicolumn{2}{|c|}{ No. $(\%) / m e a n \pm$ standard deviation (range) } \\
\hline & Preoperative $(n=76)$ & Postoperative $(n=53)$ \\
\hline $\operatorname{Qmax}(\mathrm{mL} / \mathrm{s})^{*}$ & $21.6 \pm 13.9(0-106)$ & $17.7 \pm 11.6(0-74)$ \\
\hline Postvoid residual volume (mL) & $11.2 \pm 12.3(0-100)$ & $13.9 \pm 11.3(0-50)$ \\
\hline Maximum cystometric capacity $(\mathrm{mL})$ & $316.1 \pm 106.9(85-507)$ & $346.2 \pm 126.9(97-764)$ \\
\hline Demonstrable leak & $49(64.5)$ & $7(13.2)$ \\
\hline \multicolumn{3}{|l|}{ Detrusor overactivity } \\
\hline Filling & $6(7.9)$ & $3(5.7)$ \\
\hline Cough-provoked & $20(26.3)$ & $9(17.0)$ \\
\hline Maximum urethral closure pressure $(\mathrm{cm} \mathrm{H} 2 \mathrm{O})^{+}$ & $67.7 \pm 18.5(43-134)$ & $70.6 \pm 28.4(30-167)$ \\
\hline$<42$ & $0(0)$ & $5(9.6)$ \\
\hline$\geq 42$ & $76(100.0)$ & $47(90.4)$ \\
\hline
\end{tabular}

*72 and 49 patients underwent pre- and postoperative UDS, respectively. $\$ 52$ patients underwent postoperative UDS. Qmax: maximum flow rate 
rate. Detection of DO in $34.2 \%$ of our patients enabled better counselling and follow-up management.

As a minimally invasive surgical procedure, TVT has been popular for the management of SUI since its introduction in 1996 by UImsten et al. ${ }^{(11)}$ The effectiveness of TVT is comparable to that of the traditional Burch colposuspension. In addition, complications are minimal and TVT is more cost-effective; hence, it has become the current gold standard for the management of SUI. This has been shown by several meta-analyses and randomised studies. ${ }^{(12)}$ Modifying the tape and technique (such as in TVT-Abbrevo) to further reduce complications without compromising on the results is a promising option and has been the treatment of choice at many centres since its approval by the United States Food and Drug Administration in 2010. ${ }^{(13)}$ Several studies have reported the efficacy and safety of TVT-Abbrevo at various centres during the last five years. ${ }^{(10)}$ Most studies report a cure rate of $90 \%$ with TVT and TVT-O. ${ }^{(14-16)}$ In our study, a postoperative subjective cure rate of $90.8 \%$ and objective cure rate of $86.8 \%$ (data not presented) was observed at six months. The remaining patients had significant improvement of their symptoms. Mean leak was reduced from $44.7 \pm 94.6 \mathrm{~g}$ preoperatively to $2.5 \pm 11.6$ g postoperatively among patients who showed postoperative improvement. The subjective cure rate at one-year follow-up was $90.6 \%$, and $7(77.8 \%, \mathrm{n}=9)$ patients were dry at two-year follow-up.

Only $1(1.9 \%)$ patient with mixed incontinence reported recurrence of SUI symptoms at the one-year follow-up. This patient was on anticholinergic medications (tolterodine) preoperatively and postoperatively, and was asymptomatic at the two-year follow-up. The difference in subjective and objective cures in this patient might be attributable to her mixed incontinence. Among the rest of the patients, one patient each at one month (1.4\%), six months $(1.5 \%)$, one year $(1.9 \%)$ and two years $(11.1 \%)$ reported no change in their symptoms after an initial improvement at different follow-up visits (data not presented). However, there was no demonstrable leakage in these four patients and two had normal UDS. Objective confirmation could not be made for the other two patients, as they declined UDS. A longer follow-up period and repeat UDS might have provided useful pointers for their further management. Development of de novo UI was noted in $1(3.1 \%)$ patient at the one-year follow-up. As she was 64 years old, her symptoms were likely related to age.

More than $60 \%$ of mixed incontinence cases in women resolve with the use of the TVT sling. ${ }^{(17)}$ The cure for the urge component has shown variable results, but less so than the stress component. The addition of anticholinergic medications enhances the incontinence cure rate in women with mixed incontinence. In our series, $76.3 \%$ of patients with additional symptoms of U/UI were subjectively cured at the six-month follow-up and $18.4 \%$ of patients had improvement. The proportion of patients requiring anticholinergic medications fell from $18.4 \%$ preoperatively to $11.0 \%$ postoperatively (data not presented).

Following midurethral sling surgery, varying degrees of urodynamic changes of a more obstructive pattern may be observed in the early phase. This may not relate directly to voiding dysfunction. Most patients are expected to return to baseline on long-term follow-up, as midurethral slings provide support and are tension-free. In our study, a reduction in mean Qmax was observed from $21.6 \pm 13.9 \mathrm{~mL} / \mathrm{s}$ to $17.7 \pm 11.6 \mathrm{~mL} / \mathrm{s}$ at six months postoperatively, but none of our patients had a postoperative Qmax that was less than $12 \mathrm{~mL} / \mathrm{s}$. There was a slight increase in the mean PVR from a baseline of $11.2 \pm 12.3 \mathrm{~mL}$ to $13.9 \pm 11.3 \mathrm{~mL}$. Preoperatively, all patients had an MUCP $\geq 42 \mathrm{~cm} \mathrm{H}_{2} \mathrm{O}$, but on postoperative assessment at six months, $9.6 \%$ of patients had $\mathrm{MUCP}<42 \mathrm{~cm} \mathrm{H}_{2} \mathrm{O}$. Considerable overlap can occur in MUCP values between continent and incontinent patients, and hence it is difficult to fix a cut-off value to identify these patients. For such patients, preoperative MUCP could prove helpful for choosing the sling.

Randomised studies have shown that all types of TVT slings provide a great reduction in complications and recovery time compared to conventional surgery. Obturator slings have been shown to be associated with fewer complications compared to retropubic slings. ${ }^{(18)}$ The complication rate can be further reduced by using smaller tapes, such as in TVT-Abbrevo. Vaginal perforation $(2.6 \%)$, asymptomatic small tape erosion $(4.5 \%)$ and recurrent UTI (1.5\%) were the postoperative complications encountered in our study. Various studies have reported tissue injuries in $1.7 \%$ and tape erosion in $1.5 \%$ of transobturator procedures. ${ }^{(3)}$ The median erosion after transobturator sling was reported to be $2.4 \%$ (range $0 \%-5.9 \%$ ). ${ }^{(19)}$ Previous studies have also reported mesh erosion ranging from $0 \%$ to $7.3 \%,{ }^{(17,18)}$ and the median postoperative groin or thigh pain at six months following transobturator tape was reported to be $0.9 \%$ (range $0.6 \%-5.1 \%) .{ }^{(17)}$

Persistence of groin pain beyond the immediate postoperative period is a concern in TVT-O. ${ }^{(6)}$ In a retrospective study on TVT-O at our own centre involving 419 patients, groin pain was found to have persisted for up to six months in $3.6 \%$ of patients. ${ }^{(4)}$ In contrast, randomised clinical trials with TVT-Abbrevo have reported reductions in groin pain. ${ }^{(5)}$ In our study, postoperative groin or thigh pain was $0 \%$ at six months and two years, and $1.9 \%$ at one year.

Voiding dysfunction following sling procedure has been reported in about $3 \%-11 \%$ of patients, and the symptoms may gradually develop even one year after the procedure. ${ }^{(20)}$ In our series, de novo postoperative voiding difficulty was $0 \%$ at one month, six months and one year. Catheterisation was not required in $28.9 \%$ of patients in our study (data not presented); in the remaining patients, the mean duration of catheterisation was $0.8 \pm 1.0$ day and maximum duration of catheterisation was only eight days (data not presented). The surgical intervention rate for management of post-sling voiding difficulty has been reported to be up to $5 \% .{ }^{(21)}$ None of the patients in our study required tape loosening or division.

In conclusion, TVT-Abbrevo is a technically easy, simple and effective procedure for the surgical management of female SUI. It has additional advantages compared to TVT-O, including the reduced use of mesh and minimal dissection, thereby reducing bothersome groin pain without compromising on efficacy. The 
long-term results of this TVT-Abbrevo trial, which is ongoing, have yet to be released. However, our experience with TVTAbbrevo for women with SUI for more than 22 months is encouraging.

\section{REFERENCES}

1. Abrams P. Impact of stress urinary incontinence on quality of life. Available at: www.jhasim.et/files/articlefiles/pdf/829-833(v3-800).pdf. Accessed November 30, 2015.

2. Sinclair AJ, Ramsay IN. The psychosocial impact of urinary incontinence in women. Obstet Gynaecol 2011; 13:143-8.

3. National Institute for Health and Care Excellence. Urinary incontinence in women: management. NICE guidelines [CG171]. Available at: https://www. nice.org.uk/guidance/cg171. Accessed March 15, 2014.

4. Ulmsten U, Henriksson L, Johnson P, Varhos G. An ambulatory surgical procedure under local anesthesia for treatment of female urinary incontinence. Int Urogynecol J Pelvic Floor Dysfunct 1996; 7:81-5; discussion 85-6.

5. Waltregny D, de Leval J. New surgical technique for treatment of stress urinary incontinence TVT-Abbrevo from development to clinical experience. Surg Technol Int 2012; 22:149-57.

6. Shaw JS, Jeppson PC, Rardin CR. Decreasing transobturator sling groin pain without decreasing efficacy using TVT-Abbrevo. Int Urogynecol J 2015; 26:1369-72.

7. Canel V, Thubert T, Wigniolle I, Fernandez H, Deffieux X. Postoperative groin pain and success rates following transobturator midurethral sling placement: TVT ABBREVO® system versus TVT ${ }^{\text {TM }}$ obturator system. Int Urogynecol J 2015; 26:1509-16.

8. Nygaard IE, Heit M. Stress urinary incontinence. Obstet Gynecol 2004; 104:607-20.

9. National Institute for Health and Care Excellence. Urinary incontinence: the management of urinary incontinence in women. NICE guidelines [CG 40]. Available at: https://www.nice.org.uk. Accessed March 15, 2014.

10. Karateke A, Haliloglu B, Cam C, Sakalli M. Comparison of TVT and TVT-O in patients with stress urinary incontinence: short-term cure rates and factors influencing the outcome. A prospective randomised study. Aust N Z J Obstet
Gynaecol 2009; 49:99-105.

11. Ulmsten $U$, Falconer $C$, Johnson $P$, et al. A multicentre study of tension-free vaginal tape (TVT) for surgical treatment of stress urinary incontinence. Int Urogynecol J Pelvic Floor Dysfunct 1998; 9:210-3.

12. Ward KL, Hilton P; UK and Ireland TVT Trial Group. Tension-free vaginal tape versus colposuspension for primary urodynamic stress incontinence: 5-year follow up. BJOG 2008; 115:226-33.

13. MD\&D pipeline highlights - Ethicon, EES, OCD, Vision Care. Selective highlights. In: Johnson \& Johnson [online]. Available at: http://files.shareholder. com/downloads/JNJ/0x0x509225/71182786-ff9c-4186-b754-9a7e9dbe301a/ Q32011 pipeline.pdf. Accessed May 25, 2017.

14. Long CY, Hsu CS, Wu MP, et al. Comparison of tension-free vaginal tape and transobturator tape procedure for the treatment of stress urinary incontinence. Curr Opin Obstet Gynecol 2009; 21:342-7.

15. Latthe PM, Foon R, Toozs-Hobson P. Transobturator and retropubic tape procedures in stress urinary incontinence: a systematic review and meta-analysis of effectiveness and complications. BJOG 2007; 114:522-31.

16. Nilsson CG, Palva K, Aarnio R, Morcos E, Falconer C. Seventeen years' follow-up of the tension-free vaginal tape procedure for female stress urinary incontinence. Int Urogynecol J 2013; 24:1265-9.

17. Duckett JR, Tamilselvi A. Effect of tension-free vaginal tape in women with a urodynamic diagnosis of idiopathic detrusor overactivity and stress incontinence. BJOG 2006; 113:30-3.

18. Abdel-Fattah M, Sivanesan K, Ramsay I, Pringle S, Bjornsson S. How common are tape erosions? A comparison of two versions of the transobturator tensionfree vaginal tape procedure. BJU Int 2006; 98:594-8.

19. Mahon J, Cikalo M, Varley D, Glanville J. Medicines and Health Care Products Regulatory Agency Report. MHRA. Summaries of the Safety/Adverse Effects of Vaginal Tapes/Slings/Meshes for Stress Urinary Incontinence and Prolapse. Final Report. November 2012. Available at: http://www.mhra.gov.uk/home/groups/ comms-ic/documents/websiteresources/con205383.pdf. Accessed May 25, 2017.

20. Carr LK, Webster GD. Voiding dysfunction following incontinence surgery: diagnosis and treatment with retropubic or vaginal urethrolysis. J Urol 1997; 157:821-3.

21. Taneja SS. Complications of urologic surgery. Prevention and management. 4th ed. Brazil: Saunders Elsevier, 2010. 